\title{
Engineering Practices and their Role in Post Adoption of Scrum at an Enterprise
}

\author{
Reddaiah Buduri, Srinivasa Rao Kanusu, Job Karuna Sagar. B. J, Hanumanthu Naik Korra, \\ Swetha Chinthakunta.
}

\begin{abstract}
Once Scrum process model is adopted by an enterprise, changes in the organization are common. New practices and processes are needed by the enterprise to start removing dysfunctions and problems that are identified with Scrum adoption. These variations are isolated when Scrum is applied on a single project. Some new practices, processes and techniques help to adopt Scrum at an enterprise level and are not new. They are objectively different in the way they work in current situation. In this research work engineering practices that helps in developing the projects of enterprise are illustrated. The study also focuses on how the new practices are different while using Scrum is also discussed.
\end{abstract}

Keywords: Adoption, Engineering Practices, Scrum, Sprint, Integration.

\section{INTRODUCTION}

The adoption of Scrum process is not that much simple and if properly done will give good results. Once decided to bring Scrum the practices for adoption in distributed Agile teams is very important [2], [3]. The early days of any process model when adopted in an enterprise is very important and difficult to handle [1]. When a new process model is adopted into the organization many changes at different levels can be seen especially at engineering the tasks. With these changes there will be several cautions that can be perceived. To meet this situation there exist different established practices and processes that are needed to be refined for a specific enterprise. Engineering people of an enterprise may feel

Revised Manuscript Received on November 25, 2020.

* Correspondence Author

Reddaiah. Buduri*, Department of Computer Applications, Yogi Vemana University, Kadapa (Andhra Pradesh), India. Email: b.reddaiah@yogivemanauniversity.ac.in.

Srinivasa Rao. Kanusu, Department of Computer Applications, Yogi Vemana University, Kadapa (Andhra Pradesh), India. Email: kanususrinivas@gmail.com.

Job Karuna Sagar, Department of Computer Applications, Yogi Vemana University, Kadapa (Andhra Pradesh), India. Email: jksagar2003@yahoo.com.

Hanumanthu Naik. Korra, Department of Computer Applications, Yogi Vemana University, Kadapa (Andhra Pradesh), India. Email: hanumanthukorra@gmail.com.

Swetha Chinthakunta, Department of Computer Applications, Yogi Vemana University, Kadapa (Andhra Pradesh), India. Email: reddyswetha95@gmail.com.

(C) The Authors. Published by Blue Eyes Intelligence Engineering and Sciences Publication (BEIESP). This is an open access article under the CC BY-NC-ND license (http://creativecommons.org/licenses/by-nc-nd/4.0/) rigidness when new process model like Scrum is applied, as they may be influenced by muscle memory [5]. Hence the people who start using scrum should be allowed to define and refine the new practices and process. Allowing people is very important because if the management define new practices and process, then it will be difficult for the people to adjust them to meet new situations in course of engineering. While defining new practices and process people should not waste time and effort for defining perfect practices and process. Instead they should come with one that looks suitable for the current situation. If there are any limitations in such practices and process, they will be instantly spotted by Scrum.

Sprint is the basic unit of Scrum in which development of a product can be seen and work is handled in the form of iterative cycles. [4], so the entire development can be monitored in each and every Sprint. Individual Scrum teams are responsible for developing. Such Scrum teams are frequent elements of a major project. When the work of teams is integrated then the entire work is useful for the enterprise. This integration of work is required often to track the efficiency each and every team on a project. This is possible by practices and this work focus on such practices. When it comes to Scrum process model, it needs work to be integrated in Sprint at least once.

To achieve the integration, teams involved in project development should integrate their work with other teams on daily basis and it should be a continuous task. But regular integration of each team's work may not be possible when it comes to engineering activity. As integration is needed in Scrum, the organization has to change the method of development. For this the technologies used for building and testing has to be changed and engineering skills of an organization has to be improved. The changes made in terms of technology may be limited to developer or to Scrum team. Yet majority of these enterprises may require major and constant improvements throughout the project. To overcome the engineering problem in organizations that cannot be handled within Scrum, a few engineering practices has to be included for effective integration of work.

\section{PROCEDURE FOR PAPER SUBMISSION}

The current environment in software industry mainly focuses on the requirements of customer. These requirements are not constant and they are subjected to frequent changes in course of developing the product, so that they can react to changes in demand [12]. Because of this product development to small enterprises has become a very big thought-provoking process due to

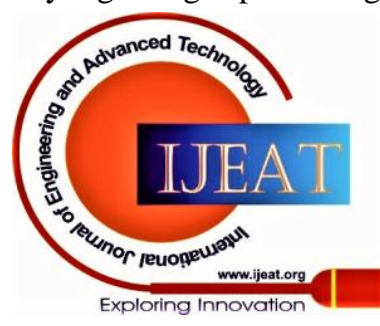


their unusual resources. With the change in different factors of developing environment many new methodologies has been proposed. Among the new methodologies Agile has its prominence [13]. This Agile group which is adaptable and flexible is also referred as light process methods [14]

Organizations using traditional process models assume and recommends with their best fit to the developing environment $[11,9,7]$. But with growth of technology and change in the needs of customers, old and traditional process models may not be suitable. So, there is every need to go for new technologies. In this way when new process model like Scrum is forced to use in an organization some changes are inevitable. Process model may be described as group of methods, practices, activities that are helpful in developing the product that includes maintaining and its related products [10]. In new process models Scrum is considered as the best practice. It helps to deliver software products with less time and in an improved and cooler way [6, 8].

An easy way to comply with the conference paper formatting requirements is to use this document as a template and simply type your text into it.

\section{PROCEDURE FOR PAPER SUBMISSION}

This work focuses on defining some important engineering practices that are essential to integrate team work while using scrum at project developing organizations.

\section{A. Multilayer System Work Organized by Functionality}

This new proposed practice aims in defining the way to organize the development of projects and in enhancing the new front-end functionality and back end infrastructure. Once the organization adapts Scrum within no time all its projects may move towards Scrum. This is because teams might be organized to their own specific functionality. Every team has to select work for a Sprint after the completion of test, design and preparing user documentation. In this course of work if once the existing infrastructure like server exceeds the capability, any such infrastructure has to be enhanced for better usage. Even though the infrastructure is enhanced as per requirement the front end should not face more difficult in accessing the back-end server.

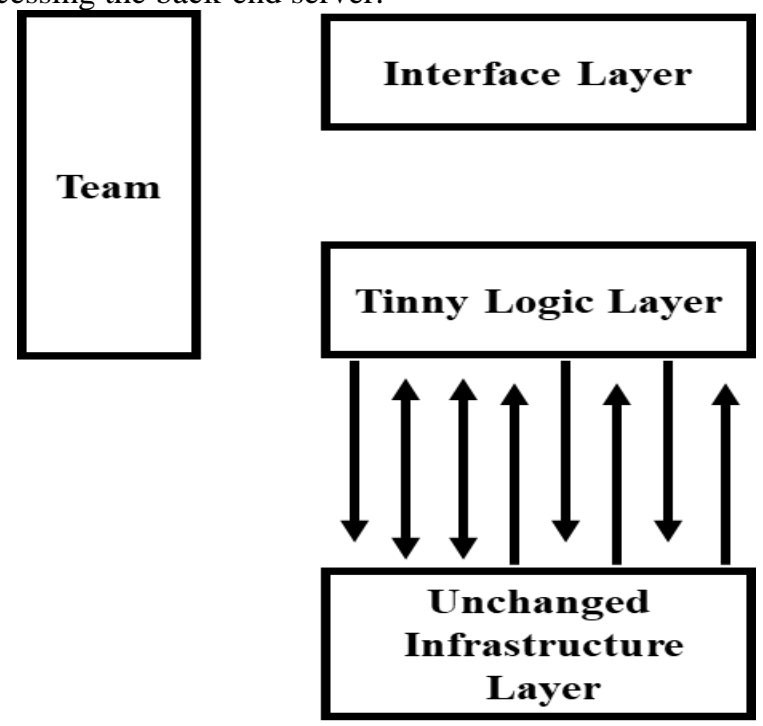

Fig. 1 Local solution needs to be developed by developing team

To execute all these tasks there should be a separate team called as infrastructure team that maintains and enhances the required infrastructures. There should be sufficient infrastructure team that can help different development teams that might be working for different projects. When the development team requires the help of inadequate infrastructure team, then the development team has to go with a local solution that does not require any infrastructure changes as shown in figure 1 .

Sometimes local solution may be far slow that product owner cannot be satisfied. In this situation it is role of Scrum Master to find an enterprise solution. As there is another solution, Scrum Master has to insist to development teams to handle other product backlog items in case if there is lack of infrastructure support. To handle these problems the development team and the infrastructure team has to synchronize their work at same Sprint. This helps them to work together as shown in figure 2.

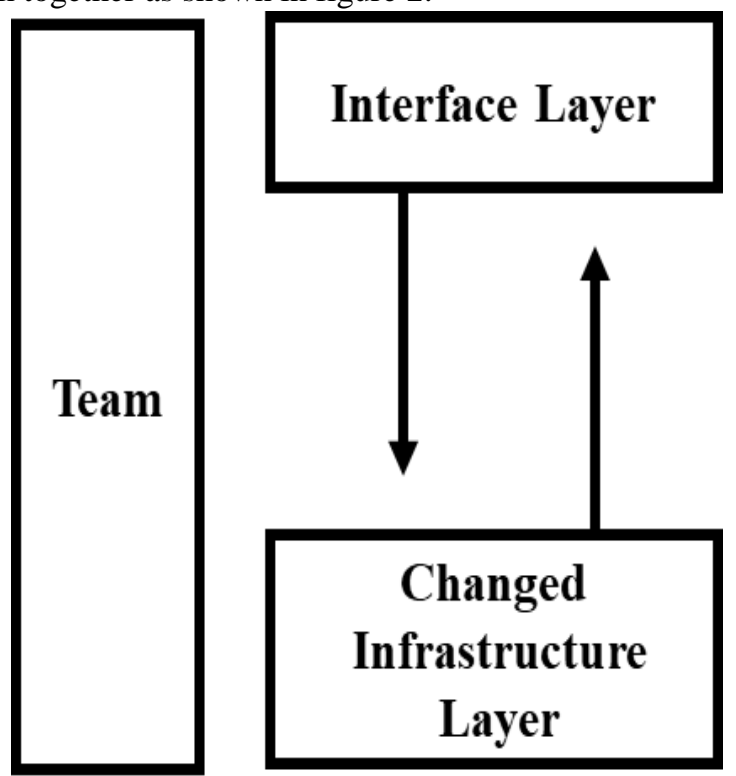

Fig. 2 Functional teams across all layers as solution for Enterprise

\section{B. Integration of Multiple Layer Systems}

Any kind of work that belongs to a product is to be divided into various architectural layers. These practices deal with the enterprises in organizing the work to get a complete product with many functions and features. Most of the products are architected into layers like interface, logic and persistence layers. General approach is that the layers can be tied together with teams that are involved in developing the functionalities across all layers. All the time these approaches may not work, that may lead to creation of new approaches. In creating new one it has meet two criteria. The first point is that team at any point of time has to know the exact current status of the ongoing project that they are developing. The second one is that the team must be capable of releasing a completed increment with all functionalities once the work is finished.

The overall functionalities of a product can be distributed into five layers. The first one collects and stores all information.

Published By:

Blue Eyes Intelligence Engineering and Sciences Publication

(c) Copvriaht: All riahts reserved.

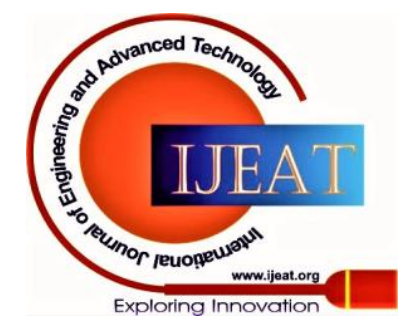


Second layer uphold customers and account information and are to be located in common server facilities. The third layer transmits and fourth deal with programming and storage. The fifth layer is for selection. The product with layers is shown in the below figure 3. After the completion of Sprint review (SR), Scrum Masters of all the layers should meet together with the product owner (PO) to take decision on Scrum of Scrums.

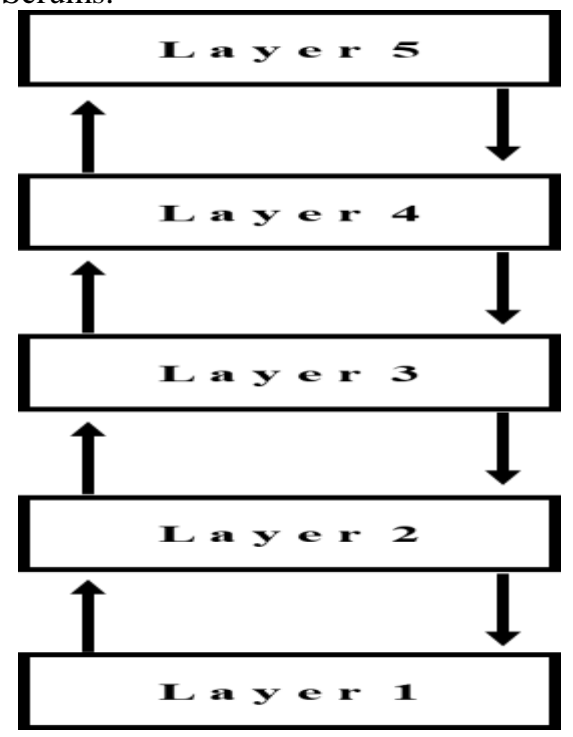

Fig. 3. General product classification in layers

Product Backlog (PB) is divided into architectural, functional, and geographical layers or mix of these layers. As a whole if Product owner is not satisfied from the product, then they may hand over unsolved Product Backlog management to other Product Owners to manage. A large project can have four to five layers of Product Backlog decomposition. The collective Product Backlog dynamically illustrates the advancement in developing a complete product. After product integration, it has to be checked and tested. This integration of efforts is shown in figure 4.

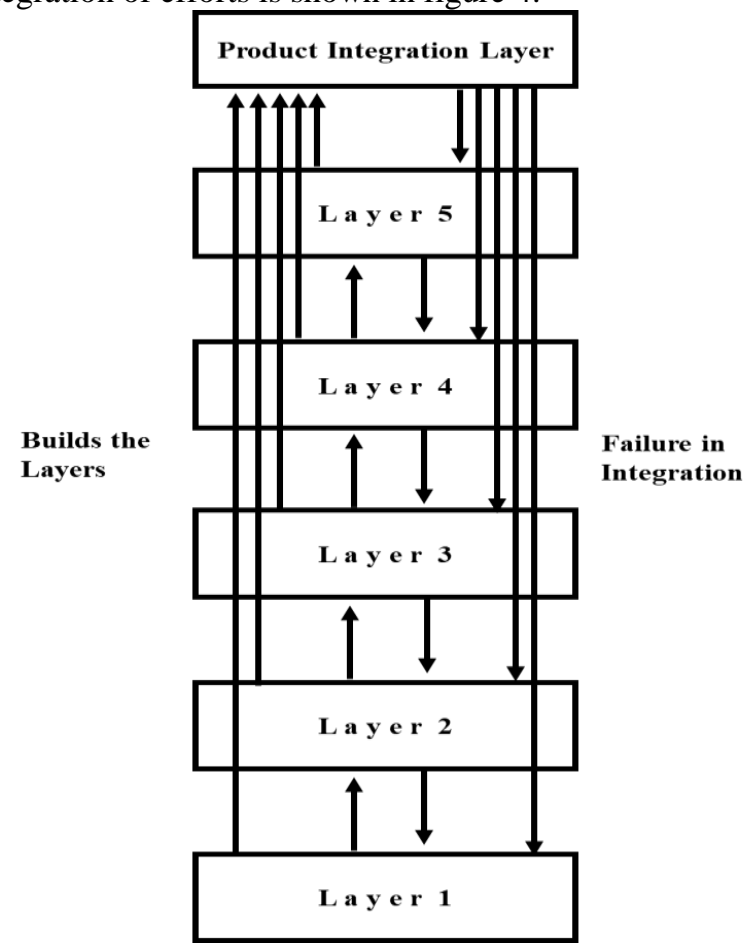

Fig. 4. Integration of Layers regularly
Scrum's check and adapted techniques require a complete integrated increment. If the increment that is checked is incomplete then the adaptation is not proper and satisfactory. If the product consists of more than five layers and varied in development cycles then consider integration is trickier and takes more time.

\section{Scrum Team Work Integrated with Non-Scrum Teams}

This practice deals with Scrum teams fitting into work of other teams. Generally, at organizational level there will be products being developed by different teams. Among these different teams some teams may be using traditional process models like waterfall process model and some may be using modern process models like Rapid application development process model (RAD) and teams that developing hardware may use proprietary process model. In these different cases all the different teams have to be managed and new model has to fit into the existing teams.

If any organizational issues like embedding, increment of functionality occurs while developing hardware related product that is being developed by using different process model related to hardware, then those issues also can be easily solved by Sprints like structures present in Scrum. The basic structure of sprint is considered as a unit of development in Scrum and it is iterative in nature. Each sprint is capable of developing deliverable products. At the end of each Sprint a Sprint review takes place where the work is reviewed to identify the new problems and those can be taken to next sprint as shown in the Figure 5.

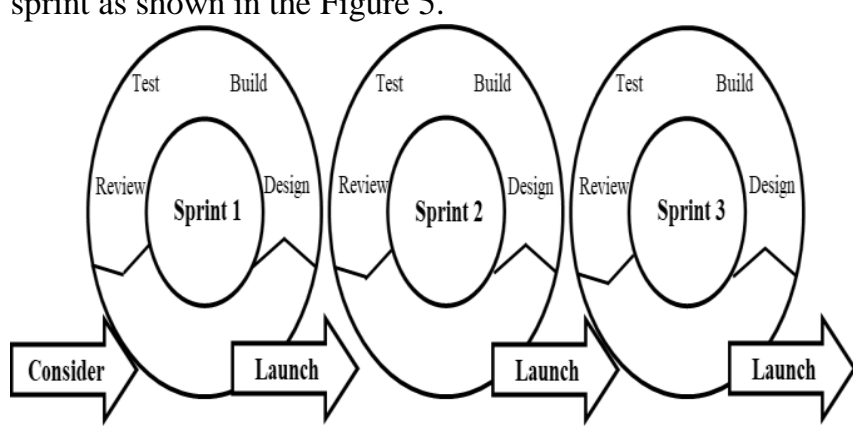

Fig.5. Overview of Sprint

In solving such problems when Scrum is adopted then software development team can use Scrum and the good quality of this process model is that it can fit to any kind of environment. While using Scrum, product owner and team extracts product backlog to find and solve the issues. As each Sprint takes a month to complete its life cycle, the hardware related issues can be fixed in each month by starting a new Sprint after collecting a group of product backlogs. If the work demands and teams prefer to have, it is also possible to reduce the span of Sprint and the span of sprint can be reduced to week or two and it is called short Sprint. This is the strength of Scrum and its Sprint.

\section{RESULTS}

The results of the new engineering practices proposed and their role in enterprise when Scrum is adopted is discussed in table 1.

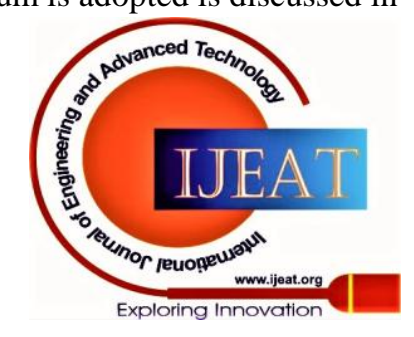




\section{Engineering Practices and their Role in Post Adoption of Scrum at an Enterprise}

Table 1. Outcome of Engineering Practices

\begin{tabular}{|c|c|c|}
\hline S. No & $\begin{array}{l}\text { Proposed } \\
\text { Engineering } \\
\text { Practice }\end{array}$ & $\begin{array}{l}\text { Role of Scrum with } \\
\text { New Engineering } \\
\text { Practices }\end{array}$ \\
\hline 1 & $\begin{array}{l}\text { Multilayer } \\
\text { System }\end{array}$ & $\begin{array}{l}\text { This practice deals with } \\
\text { acquiring the front-end } \\
\text { tools and back end tools } \\
\text { and functionalities for } \\
\text { development. After } \\
\text { acquiring, then comes } \\
\text { the art of sustaining with } \\
\text { new front-end } \\
\text { functionality and back } \\
\text { end infrastructure that is } \\
\text { more important and } \\
\text { critical in case of } \\
\text { adopting new process } \\
\text { models into the } \\
\text { organization. }\end{array}$ \\
\hline 2 & $\begin{array}{l}\text { Integration with } \\
\text { Multiple layers }\end{array}$ & $\begin{array}{l}\text { This practice focus on } \\
\text { the current status of the } \\
\text { ongoing product. This } \\
\text { deals with the release of } \\
\text { the product to the } \\
\text { customer. It focuses on } \\
\text { either an incremental } \\
\text { release to the customer, } \\
\text { so that a few } \\
\text { functionalities can be } \\
\text { used at his organization. } \\
\text { After incremental } \\
\text { release the focus is on } \\
\text { releasing the whole } \\
\text { product after } \\
\text { integration. }\end{array}$ \\
\hline 3 & \begin{tabular}{l}
\multicolumn{2}{l}{ Integration } \\
between Scrum \\
Teams and \\
Non-Scrum \\
Teams
\end{tabular} & $\begin{array}{l}\text { This practice plays } \\
\text { important role in } \\
\text { integrating the work of } \\
\text { different teams using } \\
\text { various process models, } \\
\text { on different modules of } \\
\text { product development. }\end{array}$ \\
\hline
\end{tabular}

journal uses double-blind review process, which means that both the reviewer (s) and author (s) identities concealed from the reviewers, and vice versa, throughout the review process. All submitted manuscripts are reviewed by three reviewer one from India and rest two from overseas. There should be proper comments of the reviewers for the purpose of acceptance/ rejection. There should be minimum 01 to 02-week time window for it.

\section{CONCLUSION}

The above discussed are the basic engineering practices required and can be used for integrating enterprise by using Scrum. There may be some other variants that may be required and those variants are based on the structure of the organization and they are independent to each organization. Software developing team should start by considering each increment as a period of month. As the wok progress then the length of the sprint can be reduced and it is suggestible to reduce the length of the sprint. This is good to revise the solution if not desired and can be tried again.

\section{ACKNOWLEDGMENT}

This study wishes to acknowledge Lakshmi Sridhar Movva for contributing in this work. Sridhar got Ph.D. degree for his extensive work on Agile methodologies. He has good experience in software industry as an consultant. His experience as a Scrum master who is certified a Scrum master helped a lot in developing this work.

\section{REFERENCES}

1. B. Reddaah, K. Srinivsaa Rao, "Early Days of Scrum in an Enterprise," International Journal of Engineering and Technology (IJET), Vol. 9, Issue. 4, pp. 3219 - 3225, 2017.

2. B. Reddaiah, R. Pradeep Kumar Reddy, Dr. C. Nagaraju, V. Harsha Sree, "A Novel Approach to Adopt Scrum by an Enterprise," In Pro. Of the ICAIECES, Published in Advances in Intelligent Systems and Computing - Springer, Vol. 394, pp. 645 - 654, 2015.

3. Dr. Satya Prasad Ravi, Lakshmi Sridhar Movva, B. Reddaiah, "Distributed Agile Development: Practices for building trust in team through effective communication," International Journal of Computer Science and Security (IJCSS), Vol. 1, Issue3, pp. 1 - 8, 2011.

4. B. Reddaiah, M. Padmaja, P. Vishnupriya, K. Surekha, "Handling Transition Product Backlog with Scrum off Scrum," International Journal of Advanced Information Science and Technology (IJAIST), Vol. 45, No. 45, pp. 123 - 126, 2016.

5. B. Reddaiah, K. Srinivasa Rao, "Rigidness in Applying Scrum by an Enterprise - Influenced by Muscle Memory," International Journal of Engineering and Technology (IJET), Vol. 09, No. 3, pp. 2353 - 2357, 2017.

6. Schwaber K. (2004). Agile project management with Scrum. Redmond: Microsoft Press.

7. Perrow. C.(1967). A framework for the comparative analysis of organization. Am. Soc. Rev. 23 (2), 15.

8. Schwaber K. Beedle M. (2002) Agile development ecosystems, Adission-Wesley.

9. Lawrence, P.R., Lorsch, J.W.(1967). Organization and environment; Management differentiation and Integration. Graduate School of Business Administration. Harvard University, Boston.

10. G. Cugola and C. Ghezzi. (1988) Software Processes: A Retrospective Future, In Proc. Of the Software Process Improvement and Practice Conference. pp. 101-123.

11. Burns. T., Stalker. G. (1961). The Management of Innovation. Tavistock, London.

12. RISING, L; JANOFF, N. (2000). The Scrum software development process for small teams. IEEE Software, Vol. 17, No. 4, pp. 26 - 32. doi.org/10.1109/52.854065.

13. AMBLER, S. (2002). Agile Modeling: Effective Practices for eXtreme Programming and the Unified Process. New York: Wiley Computer Publishing, pp. 402

14. FLOWER, M. (2000) Put Your Process on a Diet, Software Development.

\section{AUTHORS PROFILE}

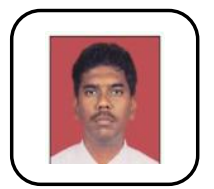

B. Reddaiah is presently working in Department of Computer Applications, Yogi Vemana University. His research areas of interest are Software engineering and Network Security. He Published 30 International papers and attended 10 National and International

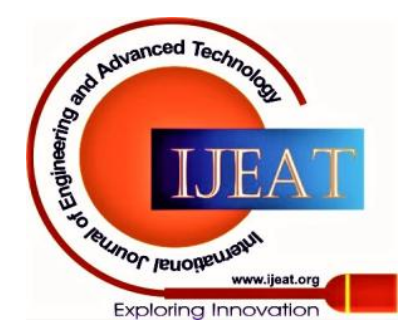


K. Srinivasa Rao is working as Assistant Professor in Department of Computer Applications, Yogi Vemana University since 2009. He is doing his Ph.D from Acharya Nagarjuna University. He Published 10 International papers and attended 4 National and $11+110$
International papers and attended 4 National and
International conferences at various places in India.

The areas of research are Digital Ima
Network Security, Software Engineering.

B. J. Job Karuna Sagar has 16 years of experience in teaching and research. His areas of interest are Network security, Hybrid routing protocols. He published papers in various journals. His core research area is Adhoc Sensor Networks.

Dr. K. HANUMANTHU NAIK an Academic Consultant, Department of computer applications, Yogi Vemana University, Kadapa. He completed his Ph. D from Sri Krishnadevaraya University, Anantapur. His research areas are computer networking and mobile sensor network. He Published 9 International papers.

C.Swetha is presently working in Department of Computer Applications, Yogi vemana University. The areas of research are Software Engineering, Security for Cloud Computing. 